\title{
Metanálise de estudos do processamento comunicativo em indivíduos com lesão vascular direita
}

\author{
Meta-analysis of communicative processing studies \\ in right-brain-damaged patients
}

\author{
Rochele Paz FONSECA ${ }^{1,2}$ \\ Maria Alice de Mattos Pimenta PARENTE ${ }^{3}$
}

\begin{abstract}
Resumo
Esta pesquisa apresenta estudos com indivíduos com lesão vascular no hemisfério direito, investigando-se o desempenho dessa população nos processamentos comunicativos discursivo, pragmático-inferencial, léxico-semântico e prosódico. A literatura de neuropsicologia atual tem enfocado cada vez mais as relações entre linguagem, comunicação, cognição e emoção através do estudo das funções do hemisfério direito em indivíduos com e sem lesão. Foram analisados os aspectos metodológicos e os resultados de 25 estudos das fontes Medline e Science Direct. Evidenciou-se que dos 357 lesados de hemisfério direito participantes, 330 (92,4\%) apresentaram alterações quantitativas e/ou qualitativas nas habilidades comunicativas avaliadas. O hemisfério direito parece desempenhar um papel importante no processamento das habilidades comunicativas discursivas, pragmático-inferenciais, léxico-semânticas e prosódicas.
\end{abstract}

Unitermos: neuropsicologia; transtornos da comunicação; linguagem; transtornos cerebrovasculares.

\begin{abstract}
This research aims to present meta-analysis studies with right-brain-damaged participants, by verifying their performance in four communicative processing domains: discursive, pragmatic-inferential, lexical-semantic and prosodic. Recent neuropsychology literature has been focusing on relations among language, communication, cognition and emotion, with a great interest in right hemisphere role in damaged and non damaged individuals' behavior. Methodological aspects and final data of 25 Medline and Sciencedirect studies were analyzed. It was observed that 330 (92.4\%) right brain damaged participants showed quantitative or qualitative impaired performance in the communicative tasks studied. It seems that right hemisphere presents an important function on communication processing, when it comes to discursive, pragmatic-inferential, lexical-semantic and prosodic abilities.
\end{abstract}

Uniterms: neuropsychology; communication disorders; language; cerebrovascular disorders.

Esta pesquisa tem por objetivo apresentar estudos com indivíduos com lesão vascular no hemisfério direito, com o intuito de investigar o desempenho dessa população nos processamentos comunicativo discursivo, pragmático-inferencial, léxico-semântico e prosódico. Pretende-se responder às seguintes questões

$\boldsymbol{\nabla} \boldsymbol{\nabla} \boldsymbol{\nabla}$

1 Pontifícia Universidade Católica do Rio Grande do Sul, Faculdade de Psicologia. Porto Alegre, RS, Brasil.

2 Universidade Federal do Rio Grande do Sul, Curso de Especialização em Psicologia Clínica; Laboratório de Neuropsico-Lingüística. Av. Ramiro Barcelos, 2600, sala 112, Santa Cecília, 90035-003, Porto Alegre, RS, Brasil. Correspondência para/Correspondence to: R.P. FONSECA. E-mail: <rochele.fonseca@gmail.com>.

3 Universidade Federal do Rio Grande do Sul, Cursos de Graduação e Pós-Graduação em Psicologia. Porto Alegre, RS, Brasil.

Agradecimento à CAPES, pelo fomento em forma de Bolsa de Doutorado no Brasil e Estágio de Doutorando na Universidade de Montreal, Canadá (processo BEX1140/05-1). 
de pesquisa: 1) indivíduos lesados de hemisfério direito apresentam déficits comunicativos? 2) caso afirmativo, em quais dos quatro processamentos comunicativos acima referidos eles apresentam déficits?

Pelas relações existentes entre linguagem, comunicação, cognição e emoção, torna-se importante que neuropsicólogos promovam cada vez mais estudos sobre o papel do hemisfério direito no processamento comunicativo. Historicamente, o hemisfério direito foi negligenciado até, aproximadamente, a década de 1950, quando sua importância para a cognição e a linguagem começou a ser redescoberta (Filskov, Grimm \& Lewis, 1981; van Lancker, 1997). Desde então, o estudo das funções cognitivo-lingüísticas enfocou a participação tanto do hemisfério esquerdo como do hemisfério direito, apesar de até os dias atuais as relações entre a linguagem e o hemisfério esquerdo serem mais enfatizadas. $O$ estudo da afasia - quadro neuropsicológico caracterizado por um prejuízo adquirido da compreensão e da expressão lingüísticas após lesão do hemisfério esquerdo (Brookshire, 2003) - foi o foco principal desde a fundação da neuropsicologia, em 1861. Tal ênfase justifica-se pelo fato de até a metade do século XX ter se pensado que o hemisfério esquerdo exercia controle exclusivo sobre a função lingüística.

As investigações neuropsicológicas sobre o papel do hemisfério direito na cognição e na comunicação provêm de duas fontes que se complementam: 1) estudos com indivíduos que sofreram lesão do hemisfério direito e 2) estudos com indivíduos neurologicamente normais. Ambos podem basear-se na verificação do desempenho cognitivo com tarefas comportamentais e/ou na observação das zonas ativadas durante a execução de tarefas lingüísticas em exames de neuroimagem.

Neste estudo, será abordada a revisão das pesquisas comportamentais com indivíduos que sofreram lesão vascular de hemisfério direito, por dois principais motivos: 1) o paradigma da lesão fundamenta o método anatomoclínico tradicional da neuropsicologia; e 2) os estudos sobre o impacto de uma lesão unilateral possibilitam a identificação da contribuição real do hemisfério lesado. A desvantagem do paradigma da lesão é a adaptação cerebral das áreas saudáveis para que ocorra a recuperação funcional. Assim, as relações

530 estabelecidas entre a função prejudicada e a lesão são hipóteses levantadas que podem corresponder ao papel real do hemisfério direito; quando intacto, ele relaciona-se com o hemisfério esquerdo.

Quanto às funções cognitivas do hemisfério direito, na literatura, algumas conseqüências cognitivas e comportamentais da lesão hemisférica direita são agrupadas sob o nome de síndrome do hemisfério direito (Brookshire, 2003; Joanette, Goulet \& Hannequin, 1990). São descritos distúrbios nas funções de orientação visuoespacial, atenção, percepção, praxia construtiva, processamento de emoção e comunicação.

Dentre os indivíduos com síndrome do hemisfério direito, observa-se uma heterogeneidade de sintomas. Assim, por exemplo, alguns pacientes apresentam alterações nas funções de orientação visuoespacial, atenção e percepção, não acompanhadas de alterações nas demais funções, enquanto outros apresentam um perfil oposto, com alterações apenas nas funções de praxia, emoção e comunicação. No que diz respeito à comunicação, as seqüelas também não são homogêneas, ou seja, enquanto alguns pacientes apresentam sintomas comunicativos nas habilidades discursivas (compreensão e produção de textos) e pragmático-inferenciais (processamento das informações lingüísticas não literais de frases e textos), outros podem apresentar apenas alterações nas habilidades léxico-semânticas (processamento da representação semântica e lexical da palavra) e prosódicas (compreensão e produção da entonação melódica das emissões lingüísticas), ou, ainda, não apresentar alterações comunicativas (Côté, Moix \& Giroux, 2004).

Alguns argumentos são apontados na literatura como possíveis justificativas para tal heterogeneidade. Sucintamente, a variabilidade de resultados pode se dever à inclusão de lesados de hemisfério direito com diferentes locais e extensões de lesão e/ou com diferentes graus de severidade do distúrbio neurológico na mesma amostra (Brookshire, 2003; Paradis, 1998; van Lancker, 1997). Os autores que descrevem o quadro típico da síndrome de hemisfério direito acabam mostrando uma visão estereotipada do indivíduo lesado de hemisfério direito (Brookshire, 2003). Talvez essa tendência de generalizar aqueles distúrbios apresentados apenas por alguns indivíduos para todos os acometidos por lesão de hemisfério direito seja uma maneira de tentar 
agrupar o conjunto de sintomas encontrados após a lesão nesse hemisfério de forma semelhante à taxonomia das afasias.

Na classificação das afasias a heterogeneidade foi amenizada pelas subclassificações. No caso da síndrome do hemisfério direito, no entanto, os estudos estão sendo realizados com praticamente um século de diferença. Assim sendo, por enquanto todos os sintomas encontram-se, ainda, agrupados sob a denominação de uma só doença. Para que a ocorrência inconsistente de seqüelas cognitivas e comportamentais após lesão de hemisfério direito possa ser entendida com maior precisão, ela deve continuar sendo estudada com alto rigor metodológico por clínicos e pesquisadores em neuropsicologia.

Na tentativa de compreender melhor a referida heterogeneidade, o presente artigo busca, através de uma metanálise descritiva de estudos com populações de lesados de hemisfério direito, investigar o desempenho desses indivíduos em quatro domínios processuais comunicativos: 1) processamento discursivo, 2) processamento pragmático-inferencial; 3) processamento léxico-semântico; e 4) processamento prosódico.

Uma vez que a avaliação do primeiro processamento geralmente envolve a compreensão e a produção do discurso conversacional e do discurso narrativo; a avaliação do segundo, a compreensão de metáforas e a compreensão de atos de fala indiretos; a avaliação do terceiro, a evocação lexical e o julgamento semântico; e a avaliação do último, a compreensão e a produção da prosódia lingüística e da prosódia emocional, tais habilidades de cada domínio processual serão enfocadas nesta metanálise (Côté et al., 2004; Joanette et al., 1990).

No que concerne ao processamento discursivo, o discurso conversacional consiste no conjunto de trocas faladas em que o tópico deve mudar durante o diálogo; o narrativo corresponde à descrição de uma série de ações e eventos relacionados cronológica e causalmente. No contexto do processamento pragmático-inferencial, a metáfora é uma figura de linguagem que expressa um significado conotativo, não literal, tal como "meu irmão é um peixe", significando "meu irmão é bom nadador" (Harley, 2001); o ato de fala indireto consiste em uma expressão lingüística que conota as intenções implícitas do falante ou escritor (Searle, 1969).
Quanto ao processamento léxico-semântico, a evocação lexical é a habilidade de produzir oral ou por escrito a maior quantidade possível de palavras em um determinado intervalo de tempo; e o julgamento semântico é a habilidade de julgar a relação de significado existente ou não entre duas ou mais palavras.

Por fim, no domínio do processamento prosódico, a prosódia lingüística corresponde ao conjunto de características entonacionais que diferencia sentenças afirmativas, interrogativas e imperativas; a prosódia emocional é o conjunto de características melódicas que diferencia expressões lingüísticas que transmitem sentimentos distintos, tais como tristeza, alegria e raiva (Joanette et al., 1990).

\section{Método}

Foram consultados 425 abstracts nas fontes Medline e Science Direct em agosto de 2005, com as palavras-chave right hemisphere e adult acrescidas por uma das que seguem: discourse, pragmatics, inference, semantics e prosody. Foram consultados abstracts de 1993 a 2005. Os estudos repetidos nas duas fontes foram contabilizados apenas uma vez. Desses 425 abstracts, foram analisados 148 artigos com ênfase nas seções Método e Resultados.

Os critérios de seleção final desses artigos para sua inclusão na metanálise foram os seguintes: 1) deveriam abordar estudos com indivíduos lesados de hemisfério direito; 2) deveriam utilizar instrumentos ou tarefas que avaliassem função(ões) correspondente(s) a um dos quatro domínios comunicativos em estudo; e 3) a lesão unilateral direita deveria ser única, de origem vascular, isquêmica ou hemorrágica, cortical, ocorrendo pela primeira vez. Foram excluídos 123 estudos que não se enquadravam nesses critérios, sendo analisados, então, 25 .

Os aspectos metodológicos e os resultados encontrados nos 25 estudos restantes foram analisados. A presente metanálise quantitativa descritiva, de acordo com Clark-Carter (2002), possibilita a quantificação das tendências das investigações buscadas na literatura através da combinação dos resultados encontrados. Desse modo, torna-se possível a identificação do número de indivíduos lesados de hemisfério direito que apresentam alterações em cada domínio processual comunicativo na amostra de estudos consultados. 


\section{Resultados e Discussão}

As seguintes informações de alguns estudos analisados nesta metanálise foram organizadas em cinco tabelas: autores, habilidades avaliadas e participantes (hemisfério direito=lesados de hemisfério direito, hemisfério esquerdo=lesados de hemisfério esquerdo e SC=sujeitos-controle). Cada estudo recebeu um número para facilitar a atual reflexão teórica e, ao final da primeira coluna de cada tabela, há o total dos estudos consultados (Tot).

Na Tabela 1, podem ser visualizados os métodos utilizados em estudos sobre o processamento do discurso conversacional em lesados de hemisfério direito. Ressalta-se que nos estudos 1, 2 e 3 as variáveis extensão e local da lesão não foram controladas, e no estudo 2 a variável tempo pós-lesão também não o foi.

Observa-se que de três estudos, dois, além de selecionarem uma amostra de lesados de hemisfério direito, também investigaram indivíduos com lesão de hemisfério esquerdo. Os estudos 1 e 3 encontraram resultados semelhantes: tanto lesados de hemisfério direito quando Ihe apresentaram dificuldades na compreensão discursiva por prejuízo no processamento inferencial, ou seja, na compreensão das informações implícitas (Gutiérrez-Calvo, 1999); já no estudo 2, 66,7\% dos lesados de hemisfério direito demonstraram dificuldades de produzir referências.

A partir da comparação entre os estudos, considerando-se os métodos utilizados e os resultados encontrados, cinco pontos de discussão podem ser levantados: 1) os estudos 1 e 3 compararam lesados de hemisfério direito com lesados de hemisfério esquerdo, enquanto o 2 o fez apenas com grupo-controle; 2) o estudo 2, além de considerar os lesados de hemisfério direito um grupo, expôs sua variabilidade individual, apresentado os escores de cada indivíduo; 3 ) os estudos 1 e 3 avaliaram especificamente o processamento inferencial na compreensão do discurso, enquanto o 2 quantificou as referências produzidas no discurso conversacional dos participantes para análise da coerência e da qualidade desse discurso; 4) as variáveis tamanho e local da lesão não foram controladas em nenhum dos estudos, mas pela inclusão do grupo de lesados de hemisfério esquerdo, os estudos 1 e 3 parearam a variável tempo pós-lesão; e 5) no estudo 3, foi evidenciada uma correlação negativa entre desempenho na compreensão de discurso conversacional e a extensão da lesão localizada no giro frontal inferior.

Os pontos de discussão 1 e 4 dizem respeito à inclusão do grupo experimental de lesados de hemisfério esquerdo, além dos lesados de hemisfério direito. Segundo Brookshire (2003), a heterogeneidade encontrada nos resultados comportamentais após lesão de hemisfério direito poderia ser reduzida pela comparação entre lesados de hemisfério direito e lesados de hemisfério esquerdo, já que essa permitiria a distinção dos efeitos da lesão cerebral de hemisfério direito dos efeitos de acometimento cerebral em geral. No entanto o autor não considera a interferência do processamento dos aspectos gramaticais da linguagem que se encontram prejudicados em qualquer tipo de afasia. Desse modo, a ausência de diferenças de desempenho entre lesados de hemisfério direito e lesados de hemisfério esquerdo nos estudos 1 e 3 pode se dever às dificuldades fonológicas, morfológicas, sintáticas e semânticas presentes no quadro de afasia. Além disso, o segundo

Tabela 1. Métodos de estudos sobre processamento discursivo com lesados de hemisfério esquerdo - discurso conversacional.

\begin{tabular}{|c|c|c|c|c|c|}
\hline \multirow{2}{*}{ Número } & \multirow{2}{*}{ Autores } & \multirow{2}{*}{ Habilidades avaliadas } & \multicolumn{3}{|c|}{ Participantes } \\
\hline & & & $\mathrm{HD}$ & $\mathrm{HE}$ & SC \\
\hline 1 & Bara, Tirassa e Zettin (1997) & $\begin{array}{l}\text { Compreensão de discurso conversacional (com processa- } \\
\text { mento inferencial) }\end{array}$ & 10 & 10 & 13 \\
\hline 2 & Chantraine, Joanette e Ska (1998) & Produção do discurso conversacional & 12 & & 14 \\
\hline 3 & $\begin{array}{l}\text { Kasher, Batori, Soroker, Gravers e } \\
\text { Zaidel (1999) }\end{array}$ & Compreensão de discurso conversacional & 27 & 31 & 27 \\
\hline Total & 3 & - & 49 & 41 & 54 \\
\hline
\end{tabular}


ponto de discussão aborda a importância de se analisar a performance individual, além da coletiva, dos lesados de hemisfério direito. Essa é uma das desvantagens de estudos de grupo.

O terceiro ponto relaciona-se às diferentes modalidades de tarefa apresentadas aos grupos; quanto mais for controlada a apresentação de estímulos discursivos que desencadeiem um processamento inferencial, maior será a demanda de compreensão e expressão de unidades lingüísticas não literais, avaliando-se, desse modo, mais especificamente as habilidades comunicativas do hemisfério direito. Por fim, o ponto 5 de discussão é relativo à função do lobo frontal anterior como uma variável interveniente no processamento comunicativo do hemisfério esquerdo. A semelhança entre as disfunções cognitivas ligadas à lesão de lobo frontal e àquelas comunicativas descritas na síndrome do hemisfério direito é relatada na literatura (Vilki, Levänen \& Servo, 2002). Essa semelhança pode se dever, pelo menos parcialmente, à inclusão de grandes proporções de lesados de hemisfério direito com lesões anteriores nos grupos estudados (McDonald, 1993). No entanto alguns autores, ao controlarem o local da lesão, encontraram as dificuldades comunicativas associadas à lesão de hemisfério direito localizada posteriormente. Desse modo, tal variável - local da lesão, excluindo-se lesões anteriores - deve ser controlada.

NaTabela 2, os mesmos aspectos metodológicos são avaliados em estudos de processamento do discurso narrativo. Nos quatro estudos, os lesados de hemisfério direito apresentaram maior dificuldade do que os lesados de hemisfério esquerdo e do que os sujeitos- -controle, mesmo naquelas tarefas em que a demanda inferencial não era explicitada na descrição dos procedimentos. Assim, tanto diferenças em relação ao processamento de linguagem não literal como à produção de coerência narrativa foram constatadas. As diferenças ficaram mais claras nas pesquisas que compararam um grupo de lesados de hemisfério direito com um grupo de indivíduos normais, sem incluírem um grupo de lesados de hemisfério esquerdo. Mais uma vez, então, a hipótese de interferência das dificuldades lingüísticas gramaticais dos lesados de hemisfério esquerdo é corroborada. Nesta análise, a discussão sobre a semelhança de quadros frontais com quadros de lesão de hemisfério direito pode ser retomada. No estudo 3 da Tabela 2, foram incluídas pessoas com lesões anteriores apenas no grupo de lesados de hemisfério esquerdo; mesmo assim, os lesados de hemisfério direito desempenharam-se pior do que os afásicos quanto à produção de discurso narrativo. Parece, então, que uma lesão de hemisfério direito não anterior acarreta dificuldades comunicativas assim como lesões localizadas em outras regiões do hemisfério direito.

Por fim, faz-se uma reflexão sobre o processamento discursivo, somando-se o total de sujeitos lesados de hemisfério direito estudados nessas pesquisas. De 83 lesados de hemisfério direito investigados através de tarefas de compreensão e produção de discurso, conversacional ou narrativo, 68 (81,9\%) apresentaram alguma dificuldade no processamento discursivo. Foram encontradas diferenças significativas em 18 lesados de hemisfério direito (32,7\%), dos 55 comparados a lesados de hemisfério esquerdo.

Tabela 2. Métodos de estudos sobre processamento discursivo com lesados de hemisfério direito - discurso narrativo.

\begin{tabular}{|c|c|c|c|c|c|}
\hline \multirow{2}{*}{ Número } & \multirow{2}{*}{ Autores } & \multirow{2}{*}{ Habilidades avaliadas } & \multicolumn{3}{|c|}{ Participantes } \\
\hline & & & $H D$ & $\mathrm{HE}$ & SC \\
\hline 1 & Beeman (1993) & $\begin{array}{l}\text { Compreensão de discurso narrativo (solicitação de processa- } \\
\text { mento inferencial) }\end{array}$ & 8 & - & 8 \\
\hline 2 & Davis, O’Neil-Pirozzi e Coon (1997) & Produção de discurso narrativo & 8 & - & 8 \\
\hline 3 & Bartels-Tobin e Hinckley (2005) & $\begin{array}{l}\text { Produção de discurso narrativo (solicitação de processa- } \\
\text { mento inferencial) }\end{array}$ & 7 & 7 & - \\
\hline 4 & $\begin{array}{l}\text { Marini, Carlomagno, Caltagirone e } \\
\text { Nocentini (2005) }\end{array}$ & Compreensão e produção de discurso narrativo & 11 & 11 & 11 \\
\hline Total & 4 & & 34 & 18 & 27 \\
\hline
\end{tabular}

HD: hemisfério direito; HE: hemisfério esquerdo; SC: sujeitos controle. 
Há, na literatura, uma discussão sobre o limite sutil entre as seqüelas comunicativas acarretadas por qualquer lesão cerebral e aquelas causadas por uma lesão de hemisfério direito ou de hemisfério esquerdo (Brookshire, 2003). No entanto a diferença de desempenho discursivo encontrada na análise desses estudos entre alguns participantes lesados de hemisfério direito e lesados de hemisfério esquerdo tende a demonstrar que componentes distintos da linguagem são comprometidos após uma lesão direita ou esquerda.

Os dados encontrados não confirmam a média de $50 \%$ de lesados de hemisfério direito com prejuízo comunicativo apresentada na literatura (Brookshire, 2003; Côté et al., 2004). Talvez tal percentual fosse ainda maior se variáveis acima discutidas, tais como local da lesão e tempo pós-lesão, fossem mais bem controladas na seleção das amostras.

\section{Processamento pragmático-inferencial}

Na Tabela 3, são apresentados os métodos utilizados nas investigações sobre o processamento metafórico após lesão de hemisfério direito. Nos três estudos consultados, ou não foi encontrada diferença significativa entre lesados de hemisfério direito e lesados de hemisfério esquerdo (estudos 1 e 3) ou apenas metade da amostra apresentou dificuldades (estudo 2). Assim como na discussão efetuada na análise dos estudos sobre processamento discursivo, neste momento também se observa uma possível interferência da dificuldade de compreensão e/ou expressão lingüística geral associada à lesão de hemisfério esquerdo. Isso se confirma na afirmação dos autores do estudo 1 sobre a constatação de que os lesados de hemisfério direito demonstraram maior dificuldade na compreensão de sentenças com conteúdo conotativo (não literal) e os lesados de hemisfério esquerdo em sentenças denotativas (literais). Para que uma inferência seja processada, primeiramente são necessários processamentos fonológico, morfológico, sintático e semântico adequados. Além disso, nos estudos 3 e 4, as amostras de lesados de hemisfério direito são extremamente reduzidas. No estudo 3, acrescenta-se o grau de complexidade da tarefa como um fator que pode minimizar as dificuldades nas habilidades pragmáticas após lesão de hemisfério direito. A identificação de palavras é muito mais fácil do que a explicação espontânea do significado de uma metáfora.

Os métodos das pesquisas abrangendo o processamento de atos de fala indiretos encontram-se na Tabela 4. Dos seis estudos analisados, em quatro foram demonstradas diferenças significativas entre o desempenho de lesados de hemisfério direito e lesados de hemisfério esquerdo ou entre lesados de hemisfério direito e normais (estudos 1, 2, 3 e 5). Os estudos 4 e 6, porém, evidenciaram, respectivamente, 50\% da amostra com desempenho prejudicado e ausência de diferença significativa entre lesados de hemisfério direito e lesados de hemisfério esquerdo, apresentando ambos os grupos dificuldades no processamento de atos de fala. No estudo 4, ressalta-se o pequeno tamanho da amostra, e no estudo 6, a possível interferência do prejuízo lingüístico após lesão de hemisfério esquerdo, assim como a correlação, mais uma vez encontrada, entre lesão frontal e desempenho do grupo de lesados de hemisfério esquerdo. Diferentemente do achado encontrado no estudo 3 da Tabela 1, no estudo 6 da Tabela 4, não houve correlação entre local da lesão (anterior) e prejuízo da compreensão de atos de fala apresentado pelos lesados de hemisfério direito. Essa assistematicidade da

Tabela 3. Métodos de estudos sobre processamento pragmático-inferencial com lesados de hemisfério direito - compreensão de metáforas.

\begin{tabular}{|c|c|c|c|c|c|}
\hline \multirow{2}{*}{ Número } & \multirow{2}{*}{ Autores } & \multirow{2}{*}{ Habilidades avaliadas } & \multicolumn{3}{|c|}{ Participantes } \\
\hline & & & $\mathrm{HD}$ & $\mathrm{HE}$ & $\mathrm{SC}$ \\
\hline 1 & Winner e Gardner (1977) & Compreensão de metáforas & 22 & 35 & 10 \\
\hline 2 & Champagne, Desauels e Joanette (2003) & Compreensão de metáforas & 4 & - & 4 \\
\hline 3 & Hillert (2004) & $\begin{array}{l}\text { Compreensão de expressões literais e de expressões } \\
\text { idiomáticas }\end{array}$ & 1 & 4 & 1 \\
\hline Total & 3 & - & 27 & 39 & 15 \\
\hline
\end{tabular}

534

HD: hemisfério direito; HE: hemisfério esquerdo; SC: sujeitos controle. 
Tabela 4. Métodos de estudos sobre processamento pragmático-inferencial com lesados de hemisfério direito - compreensão de atos de fala indiretos.

\begin{tabular}{|c|c|c|c|c|c|}
\hline \multirow{2}{*}{ Número } & \multirow{2}{*}{ Autores } & \multirow{2}{*}{ Habilidades avaliadas } & \multicolumn{3}{|c|}{ Participantes } \\
\hline & & & $\mathrm{HD}$ & $\mathrm{HE}$ & SC \\
\hline 1 & Foldi (1987) & Atos de fala literais (diretos) e pragmático (indiretos) & 19 & 17 & 16 \\
\hline 2 & Weylman, Brownell, Roman e Gardner (1989) & Atos de fala indiretos (do tipo pedidos indiretos) & 14 & - & 14 \\
\hline 3 & McDonald (2000) & Compreensão e produção de atos de fala indiretos & 18 & - & 20 \\
\hline 4 & Champagne, Desauels e Joanette (2003) & Compreensão de atos de fala & 4 & - & 4 \\
\hline 5 & $\begin{array}{l}\text { Champagne, Virbel, Nespoulous e Joanette } \\
\text { (2003) }\end{array}$ & Compreensão de atos de fala indiretos & 20 & - & 20 \\
\hline 6 & Soroker et al. (2005) & Compreensão de atos de fala & 27 & 31 & 21 \\
\hline Total & 6 & - & 102 & 48 & 95 \\
\hline
\end{tabular}

HD: hemisfério direito; HE: hemisfério esquerdo; SC: sujeitos controle.

ocorrência de correlações indica que a semelhança entre síndrome frontal e síndrome do hemisfério direito deve ser mais bem investigada.

De 129 lesados de hemisfério direito avaliados quanto ao processamento pragmático-inferencial, tanto de metáforas quanto de atos de fala indiretos, 124 (96,12\%) apresentaram prejuízo no desempenho. Dos 69 lesados de hemisfério direito comparados a lesados de hemisfério esquerdo, 41 lesados de hemisfério direito $(59,4 \%)$ diferenciaram-se dos lesados de hemisfério esquerdo. Apesar de muitas variáveis também não terem sido controladas nos estudos sobre esse processamento, tais como tempo pós-lesão e extensão da lesão, as tarefas foram mais uniformes e mais estudos que não incluíram amostras de afásicos foram observados. De tal forma, a variável prejuízo lingüístico gramatical (no nível do som, da palavra ou da frase), presente na população de lesados de hemisfério esquerdo, provavelmente não interferiu tanto nas pesquisas envolvendo processamento pragmático-inferencial como nos estudos sobre processamento discursivo.

\section{Léxico-semântico}

No estudo de Beausoleil, Fortin, Le Blanc e Joanette (2003), o processamento léxico-semântico foi avaliado a partir de uma tarefa de evocação lexical livre. Participaram dessa investigação 30 lesados de hemisfério direito, 30 lesados de hemisfério esquerdo e 30 sujeitos-controle (estudo 1). Nocentini, Goulet, Roberts e Joanette (2001) avaliaram o processamento léxico-semântico através de uma prova de julgamento semântico, com a participação de 15 lesados de hemisfério direito, 15 lesados de hemisfério esquerdo e 15 sujeitos-controle (estudo 2). No estudo 1, tanto os indivíduos lesados de hemisfério direito quanto lesados de hemisfério esquerdo produziram menor quantidade de palavras por intervalo de tempo, quando comparados aos sujeitos controle. Os lesados de hemisfério direito produziram mais categorias semânticas que os lesados de hemisfério esquerdo, mas menos do que os sujeitos-controle. Os lesados de hemisfério direito produziram palavras menos prototípicas (representativas de uma categoria semântica) do que os lesados de hemisfério esquerdo e sujeitos-controle. Do mesmo modo, no estudo 2, os lesados de hemisfério direito apresentaram desempenho pior do que os sujeitos-controle.

A ausência de diferenças significativas entre lesados de hemisfério direito e lesados de hemisfério esquerdo era esperada na avaliação desse processamento, pois as habilidades de evocar palavras e de julgar a relação semântica entre vocábulos requerem, mais do que as outras habilidades comunicativas em pauta, a participação ativa dos dois hemisférios. Salienta-se a hipótese de que os lesados de hemisfério direito apresentaram maior dificuldade no estudo 2 em identificar as relações de localização entre duas palavras devido à dificuldade cognitiva de orientação visuoespacial, referida como um distúrbio comum na síndrome do hemisfério direito.

Do total de 45 lesados de hemisfério direito, participantes dos dois estudos, 100\% apresentaram dificuldade quantitativa ou qualitativa nas habilidades de evocação lexical e julgamento semântico, demonstrando que mesmo o processamento léxico-semântico sendo um domínio processual comunicativo mais 
relacionado ao hemisfério esquerdo, uma lesão vascular no hemisfério direito pode acarretar alterações semeIhantes àquelas presentes nos quadros afásicos. Houve diferença significativa entre os 45 lesados de hemisfério direito e os 45 lesados de hemisfério esquerdo.

\section{Processamento prosódico}

No que diz respeito à prosódia lingüística, três estudos foram analisados. Pell e Baum (1997) - estudo 1 - avaliaram nove lesados de hemisfério direito, dez lesados de hemisfério esquerdo e nove sujeitos-controle através de uma tarefa de percepção desse tipo de prosódia. Nenhum dos grupos apresentou dificuldades em perceber as características prosódicas lingüísticas dos modos afirmativo, interrogativo e imperativo (acurácia mínima de $80 \%$ ), mas os sujeitos-controle apresentaram melhor desempenho. Na pesquisa de Pell (1999), estudo 2, em que dez lesados de hemisfério direito e dez sujeitos-controle foram examinados em uma prova de produção de prosódia lingüística, os lesados de hemisfério direito produziram sentenças com menor variação de freqüência (análise computadorizada) e menor confiabilidade de transmissão de ênfase (análise subjetiva por ouvintes). O terceiro estudo, de Shah, Baum e Dwivedi (2006), baseou-se em uma tarefa de resolução de ambigüidade sintática através da compreensão e da produção de prosódia lingüística. Participaram dessa investigação sete lesados de hemisfério direito, seis lesados de hemisfério esquerdo e oito sujeitos-controle. Não foram observadas diferenças significativas entre grupos, com lesados de hemisfério direito e sujeitoscontrole apresentando melhor consistência de freqüência fundamental.

Desses três estudos, apenas o estudo 2 demonstrou diferenças significativas entre lesados de hemisfério direito e sujeitos normais. A disprosódia - alteração na compreensão e/ou produção de entonação melódica - é freqüentemente associada à síndrome do hemisfério direito (Joanette et al., 1990). Entretanto, se as distinções metodológicas entre os estudos 1 e 3 e o estudo 2 forem observadas, a não inclusão de um grupo de lesados de hemisfério esquerdo no estudo 2 será constatada. Desse modo, a influência dos distúrbios específicos de linguagem após lesão de hemisfério esquerdo não ocorreu nesta investigação. Além disso, a variável tempo pós-lesão parece também ter influenciado, uma vez que no

536 estudo 3 foram incluídos indivíduos com no mínimo três anos pós-lesão. Sabe-se que a partir de seis meses, grande parte da recuperação funcional espontânea já foi completada (Kelley, 2003; Sarno \& Levita, 1971).

Quanto à prosódia emocional, foram inseridos na metanálise seis estudos. Na pesquisa de Pell e Baum (1997), estudo 1, nove lesados de hemisfério direito, dez lesados de hemisfério esquerdo e dez sujeitos-controle realizaram uma tarefa de percepção prosódica. Nenhum dos grupos apresentou dificuldades em perceber as características prosódicas emocionais de raiva, tristeza e alegria, sem diferenças significativas entre grupos. No estudo 2, de Wertz, Henschel, Auther, Ashford e Kirshner (1998), 20 lesados de hemisfério direito e 18 sujeitoscontrole executaram uma prova de produção, repetição e compreensão de prosódia emocional no discurso espontâneo. Todos lesados de hemisfério direito apresentaram prejuízo na produção de prosódia emocional no discurso conversacional espontâneo, assim como demonstraram maior dificuldade em repetir e compreender estímulos prosódicos emocionais (sentimentos: alegria, tristeza, raiva, surpresa, choro, desinteresse), quando comparados aos sujeitos-controle.

Na investigação de Pell (1999), estudo 3, a produção de prosódia emocional foi solicitada para dez lesados de hemisfério direito e dez sujeitos-controle. Os lesados de hemisfério direito produziram sentenças com menor variação de freqüência (análise computadorizada) e menor confiabilidade de transmissão de ênfase nas diferentes emoções (análise subjetiva por ouvintes). No estudo 4, Charbonneau, Scherzer, Aspirot e Cohen (2003) investigaram a discriminação, identificação, imitação e produção de prosódia emocional em 15 lesados de hemisfério direito, 17 lesados de hemisfério esquerdo e 16 sujeitos-controle. Os lesados de hemisfério direito apresentaram pior desempenho que os outros grupos nas tarefas de discriminação, imitação e produção dos sentimentos de medo, tristeza e raiva. Kucharska-Pietura, Philips, Gernand e David (2003), no estudo 5, examinaram a percepção de prosódia emocional em 30 lesados de hemisfério direito, 30 lesados de hemisfério esquerdo e 50 sujeitos-controle. Os lesados de hemisfério direito apresentaram desempenho pior do que os lesados de hemisfério esquerdo, ambos com desempenho inferior ao dos sujeitos-controle.

Pell (2006), estudo 6, utilizando uma tarefa de discriminação, identificação e graduação de prosódia 
emocional (cinco emoções), examinou nove lesados de hemisfério direito, 11 lesados de hemisfério esquerdo e 12 sujeitos-controle. Tanto os lesados de hemisfério direito quanto os lesados de hemisfério esquerdo desempenharam-se pior do que o grupo-controle, tendo os primeiros apresentado dificuldades em todos os estímulos independentemente da presença de conteúdo semântico, e os últimos, maior dificuldade na presença de conteúdo semântico.

Dessas seis pesquisas, foram encontradas diferenças significativas em quatro: estudos 2, 3, 4 e 5. Os estudos que não evidenciaram diferenças de desempenho entre grupos incluíram em suas amostras um grupo de lesados de hemisfério esquerdo. Portanto, do total de 100 participantes de lesados de hemisfério direito dos sete estudos consultados sobre as duas prosódias, em 93 foram observadas dificuldades prosódicas. Dos 70 lesados de hemisfério direito comparados a um grupo de lesados de hemisfério esquerdo, 54 (77,1\%) demonstraram diferenças significativas.

Ao se enfocar o processamento comunicativo como um todo, observando-se os resultados dos estudos dos quatro domínios processuais estudados, evidencia-se que dos 357 lesados de hemisfério direito participantes, foram constatadas dificuldades discursivas, pragmático-inferenciais, léxico-semânticas ou prosódicas em 330 deles (92,4\%). Além disso, daqueles 239 lesados de hemisfério direito comparados a um grupo de lesados de hemisfério esquerdo, 158 (66,1\%) diferenciaram-se do último grupo. Dessa forma, em geral, a maioria dos lesados de hemisfério direito apresenta seqüelas comunicativas na amostra de estudos analisada, assim como a maior parte dessa amostra distingue-se dos lesados de hemisfério esquerdo, apresentando um pior desempenho do que esses últimos. A ausência de diferenças entre lesados de hemisfério direito e lesados de hemisfério esquerdo no restante da amostra $(33,9 \%)$ pode ter ocorrido graças à inclusão de lesados de hemisfério esquerdo com algum grau de afasia, cujo prejuízo lingüístico gramatical associado não permite um adequado processamento dos demais aspectos comunicativos avaliados.

\section{Considerações Finais}

De um modo geral, considerando a metanálise de investigações sobre os quatro domínios processuais comunicativos, pode-se afirmar que a heterogeneidade referida na literatura foi confirmada nesta revisão: alguns participantes lesados de hemisfério direito apresentam dificuldades comunicativas, outros não. Isso pode se dever à influência de variáveis não controladas (características distintas das lesões hemisféricas - local e extensão da lesão, tempo pós-lesão - ou características sociodemográficas dos indivíduos) ou ser inerente à síndrome do hemisfério direito propriamente dita. No entanto a porcentagem de 50\% de lesados de hemisfério direito com seqüelas comunicativas indicada tradicionalmente na literatura deve ser mais detalhadamente investigada, já que não foi confirmada nesta metanálise.

Assim, apesar dos diferentes resultados relatados, predomina a conclusão de que a maioria dos indivíduos lesados de hemisfério direito apresenta déficits comunicativos, englobando alterações discursivas, pragmático-inferenciais, léxico-semânticas e/ou prosódicas. Evidenciou-se que o processamento de informações literais é efetuado predominantemente pelo hemisfério esquerdo e os processamentos discursivo, pragmático-inferencial, léxico-semântico e prosódico, com ênfase no processamento de informações não literais, é realizado principalmente pelo hemisfério direito. Uma dissociação dupla - aspectos não-gramaticais totalmente preservados após lesados de hemisfério esquerdo e totalmente prejudicados após lesados de hemisfério direito - não pôde ser inferida a partir dos estudos analisados. Há, então, um papel ativo do hemisfério direito no processamento comunicativo-lingüístico.

\section{Referências}

Bara, B. G., Tirassa, M., \& Zettin, M. (1997). Neuropragmatics: neuropsychological constraints on formal theories of dialogue. Brain and Language, 59 (1), 7-49.

Bartels-Tobin, L. R., \& Hinckley, J. L. (2005). Cognition and discourse production in right hemisphere disorder. Journal of Neurolinguistics, 12 (6), 461-477.

Beausoleil, N., Fortin, R., Le Blanc, B., \& Joanette, Y. (2003). Unconstrained oral naming performance in right- and left-hemisphere-damaged individuals: when education overrides the lesion. Aphasiology, 17 (2), 143-158.

Beeman, M. (1993). Semantic processing in the right hemisphere may contribute to drawing inferences from discourse. Brain and Language, 44 (1), 80-120.

Brookshire, R. H. (2003). Introduction to neurogenic communication disorders. Missouri: Mosby. 
Champagne, M., Desautels, M., \& Joanette, Y. (2003). Accounting for the pragmatic déficit in RHD individuals: a multiple case study. Brain and Language, 87 (1), 210-211.

Champagne, M., Virbel, J., Nespoulous, J., \& Joanette, Y. (2003). Impact of right hemispheric damage on a hierarchy of complexity evidenced in young normal subjects. Brain and Cognition, 53 (2), 152-157.

Chantraine, Y., Joanette, Y., \& Ska, B. (1998). Conversational abilities in patients with right hemisphere damage. Journal of Neurolinguistics, 11 (1-2), 21-32.

Charbonneau, S., Scherzer, B. P., Aspirot, D., \& Cohen, H. (2003). Perception and production of facial and prosodic emotion by chronic CVA patients. Neuropsychologia, 41 (5), 605-613

Clark-Carter, D. (2002). Doing quantitative psychological research: from design to report. New York: Psychology Press.

Côté, H., Moix, V., \& Giroux, F. (2004). Évaluation des troubles de la communication des cérébrolésés droits. Rééducation Orthophonique, 219 (4), 107-122.

Davis, G. A., O'Neil-Pirozzi, T. M., \& Coon, M. (1997). Referential cohesion and logical coherence of narration after right hemisphere stroke. Brain and Language, 56 (2), 183-210.

Filskov, S. B., Grimm, B. H., \& Lewis, J. A. (1981). Brainbehavior relationships. In S. B. Filskov, \& T. J. Boll. Handbook of clinical neuropsychology (pp.39-73). New York: John Wiley and Sons.

Foldi, N. S. (1987). Appreciation of pragmatic interpretations of indirect commands: comparison of right and left hemisphere brain-damaged patients. Brain and Language, 31 (1), 88-108

Gutiérrez-Calvo, M. (1999). Inferencias en la comprensión del lenguaje. In M. Veja \& F. Cuetos (Orgs.), Psicolinguistica del español (pp.231-270). Madrid: Trotta.

Harley, T. (2001). The psychology of language. New York: Psychology Press.

Hillert, D. G. (2004). Spared access to idiomatic and literal meanings: a single-case approach. Brain and Language, 89 (1), 207-215.

Joanette, Y., Goulet, P., \& Hannequin, D. (1990). Right hemisphere and verbal communication. New York: springer.

Kasher, A., Batori, G., Soroker, N., Gravers, D., \& Zaidel, E. (1999). Effects of roght and left hemisphere damage on understanding conversational implicatures. Brain and Language, 68 (3), 566-590.

Kelley, R. E. (2003). Afecções dos vasos cerebrais. In W. J. Weinwe \& C. G. Goetz. Neurologia para o não-especialista (pp.69-83). São Paulo: Santos.

Kucharska-Pietura, K., Philips, M. L., Gernand, W., \& David, A.S. (2003). Perception of emotions from faces and voices following unilateral brain damage. Neuropsychologia, 41 (8), 1082-1090.

Marini, A., Carlomagno, S., Caltagirone, C., \& Nocentini, U. (2005). The role played by the right hemisphere in the organization of complex textual structures. Brain and Language, 93 (1), 46-54.
McDonald, S. (1993). Viewing de brain sideways? Frontal versus right hemisphere explanations of nonaphasic language disorders. Aphasiology, 7 (4), 535-549.

McDonald, S. (2000). Exploring the cognitive basis of right-hemisphere pragmatic language disorders. Brain and Language, 75 (1), 82-107.

Nocentini, U., Goulet, P., Roberts, P. M., \& Joanette, Y. (2001). The effects of left- versus right-hemisphere lesions on the sensitivity to intra- and interconceptual semantic relationships. Neuropsychogia, 39 (5), 443-451.

Paradis, M. (1998). The other side of language: pragmatic competence. Journal of Neurolinguistics, 11 (1-2), 1-10.

Pell, M. D. (1999). Fundamental frequency encoding of linguistic and emotional prosody by right hemisphere-damaged speakers. Brain and Language, 69 (2), 161-192.

Pell, M. D. (2006). Cerebral mechanisms for understanding emotional prosody in speech. Brain and Language, 96 (2), 221-234.

Pell, M. D., \& Baum, S. R. (1997). The ability to perceive and comprehend intonation in linguistic and affective contexts by brain-damaged adults. Brain and Language, 57 (1), 80-99.

Sarno, M. T., \& Levita, E. (1971). Natural course of recovery in severe aphasia. Archives of Physical Medicine and Rehabilitation, 52 (2), 175-178.

Searle, J. R. (1969). Speech acts. Cambridge: Cambridge University Press.

Shah, A.P., Baum, S.R., \& Dwivedi, V.D. (2006). Neural substrates of linguistic prosody: evidence from syntactic disambiguation in the productions of brain-damaged patients. Brain and Language, 96 (1), 78-89.

Soroker, N., Kasher, A., Giora, R., Batori, G., Corn, C., Gil, M., \& Zaidel, E. (2005). Processing of basic speech acts following localized brain damage: a new light on the neuroanatomy of language. Brain and Cognition, 57 (2), 214-217.

Van Lancker, D. V. (1997). Rags to riches: our increasing appreciation of cognitive and communicative abilities of the human right cerebral hemisphere. Brain and Language, 57 (1), 1-11.

Vilkki, J., Levänen, S., \& Servo, A. (2002). Interference in dual-fluency tasks after anterior and posterior cerebral lesions. Neuropsychologia, 40 (3), 340-348.

Wertz, R. T., Henschel, C. R., Auther, L. L., Ashford, J. R., \& Kirshner, H. S. (1998). Affective prosodic disturbance subsequent to right hemisphere stroke: a clinical application. Journal of Neurolinguistics, 11 (1-2), 89-102.

Weylman, S. T., Brownell, H. H., Roman, M., \& Gardner, H. (1989). Appreciation of indirect requests by left- and right-brain-damaged patients: the effect of verbal context and conventionality of wording. Brain and Language, 36 (4), 580-591.

Winner, E., \& Gardner, H. (1977). The comprehension of metaphor in brain-damaged patients. Brain, 100 (4), 717-729.

Recebido em: 20/2/2006

Versão final reapresentada em: 25/7/2006

Aprovado em: 4/9/2006 